\title{
Long-term outcomes in patients undergoing vitrectomy for retinal detachment due to viral retinitis
}

This article was published in the following Dove Press journal:

Clinical Ophthalmology

16 July 2015

Number of times this article has been viewed

\author{
David RP Almeida' \\ Eric K Chin' \\ Ryan M Tarantola' \\ Elizabeth O Tegins' \\ Christopher A Lopez' \\ Herbert Culver Boldt ${ }^{1}$ \\ Karen M Gehrs' \\ Elliott H Sohn' \\ Stephen R Russell' \\ James C Folk' \\ Vinit B Mahajan ${ }^{1,2}$ \\ 'Department of Ophthalmology and \\ Visual Sciences, ${ }^{2}$ Omics Laboratory, \\ University of lowa Hospitals and \\ Clinics, lowa City, IA, USA
}

Purpose: To determine the outcomes in patients with rhegmatogenous retinal detachment (RRD) secondary to viral retinitis.

Patients and methods: This was a retrospective, consecutive, noncomparative, interventional case series of 12 eyes in ten patients with RRD secondary to viral retinitis. Results of vitreous or aqueous biopsy, effect of antiviral therapeutics, time to retinal detachment, course of visual acuity, and anatomic and surgical outcomes were investigated.

Results: There were 1,259 cases of RRD during the study period, with 12 cases of RRD secondary to viral retinitis (prevalence of $0.95 \%$ ). Follow-up was available for a mean period of 4.4 years. Varicella zoster virus was detected in six eyes, herpes simplex virus in two eyes, and cytomegalovirus in two eyes. Eight patients were treated with oral valacyclovir and two patients with intravenous acyclovir. Lack of optic nerve involvement correlated with improved final visual acuity of $20 / 100$ or greater. Pars plana vitrectomy $(n=12)$, silicone-oil tamponade $(n=11)$, and scleral buckling $(\mathrm{n}=10)$ provided successful anatomic retinal reattachment in all cases, with no recurrent retinal detachment and no cases of hypotony during the follow-up period.

Conclusion: Varicella zoster virus was the most frequent cause of viral retinitis, and lack of optic nerve involvement was predictive of a favorable visual acuity prognosis. Vitrectomy with silicone-oil tamponade and scleral buckle placement provided stable anatomical outcomes.

Keywords: viral retinitis, acute retinal necrosis, herpetic retinitis, vitrectomy, retinal detachment

\section{Introduction}

Viral retinitis was first described as acute retinal necrosis (ARN) by Urayama et al in $1971,{ }^{1}$ and typically manifests as a progressive occlusive necrotizing vasculitis involving retinal and choroidal vasculature with subsequent retinal detachment. ${ }^{2,3}$ Bilateral viral retinitis, also known as bilateral ARN, occurs in approximately $13 \%-33 \%$ of cases. ${ }^{3,4}$ The incidence of viral retinitis is equal between males and females, and estimated at 0.63 cases per million population per year with a large variation in age of presentation. ${ }^{5,6}$ Diagnosis is based on the American Uveitis Society clinical criteria, which includes focal well-demarcated areas of retinal necrosis located in the peripheral retina, rapid and circumferential progression of necrosis, evidence of occlusive vasculopathy, and prominent inflammatory reaction in the vitreous and anterior chamber. ${ }^{7}$

Etiology in immunocompetent people is varicella zoster virus (VZV) in 50\%, herpes simplex virus (HSV) in 25\%, Epstein-Barr virus in 15\%, and cytomegalovirus (CMV) in $1 \%$. CMV is much more common in immunocompromised patients. ${ }^{8-10}$ Polymerase chain-reaction (PCR) analysis of aqueous and vitreous samples is the gold standard for diagnosis (sensitivity 95\%, specificity 97\%), ${ }^{11-13}$ and for monitoring disease course
Correspondence: Vinit B Mahajan University of lowa Carver College of Medicine, 200 Hawkins Drive, lowa City, IA 52242, USA

Tel + I 3193563185

Fax + I 3193560363

Email vinit-mahajan@uiowa.edu 
and response to therapy via viral load quantification. ${ }^{14-16} \mathrm{Cur}-$ rently, oral medications, such as acyclovir ( $800 \mathrm{mg}$ five times per day), ${ }^{17}$ valacyclovir ( $1 \mathrm{~g}$ ter in die [TID three times a day $\}]),{ }^{18}$ and famciclovir (500 $\mathrm{mg}$ TID) $)^{19}$ are recommended, and seem to have similar efficacy to the traditional intravenous acyclovir $\left(1,500 \mathrm{mg} / \mathrm{m}^{2}\right.$ body surface area) regimen. ${ }^{20}$ Oral agents like valacyclovir (Valtrex; GlaxoSmithKline PLC, London, UK) and famciclovir (Famvir; Novartis International AG, Basel, Switzerland) have superior bioavailability and central nervous system penetration compared to acyclovir, and seem to have utility in both the initial treatment and maintenance therapy of patients with viral retinitis. ${ }^{3}$

Rhegmatogenous retinal detachment (RRD) is common in viral retinitis, occurring in $20 \%-75 \%$ of eyes, with resultant poor visual outcomes. ${ }^{21-24}$ RRD usually occurs after the acute phase of infection, and is secondary to vitreous traction on necrotic retina and inflammatory membranes. ${ }^{25}$ The role of prophylactic laser photocoagulation to prevent RRD is unclear, ${ }^{26}$ and the optimal approach to vitrectomy for RRD remains difficult to ascertain. ${ }^{6}$ In recent years, surgical instrumentation and antiviral regimens have changed dramatically, and there is no single treatment strategy that has been identified as the standard of care. Moreover, no variables have been identified to be predictive of surgical success for RRD or prognostic of visual outcomes. This study investigated the long-term visual and anatomic outcomes in cases with RRD secondary to viral retinitis to determine effective medical treatment and surgical approaches in this challenging group of patients.

\section{Patients and methods}

The study protocol was approved by the University of Iowa Institutional Review Board for Human Subjects Research, and adhered to the tenets set forth in the Declaration of Helsinki. Operative reports, surgical logs, and charts from a consecutive group of patients undergoing surgical repair of RRD at the University of Iowa between 2006 and 2013 were reviewed to identify subjects with a diagnosis of viral retinitis. Diagnosis of viral retinitis was based on American Uveitis Society clinical criteria. ${ }^{7}$ Results of viral PCR detection from aqueous or vitreous biopsies were analyzed for identification of the putative herpes virus.

The records of all consecutive patients with RRD secondary to viral retinitis were reviewed for demographic data, clinical course, ophthalmic findings, and anatomic outcomes. Specifically, patient immune status, aqueous and vitreous PCR diagnosis, medical therapy, time to RRD, and surgical technique were reviewed and tabulated. Snellen visual acuity was recorded in a standardized clinical manner. The mean, median, and standard deviation of presenting and final vision were calculated after the conversion to the logarithm of the minimum angle of resolution (logMAR) equivalent of each patient's Snellen visual acuity. A visual acuity of "counts fingers" or hand motion (HM) were recorded as 20/2,000 (logMAR 2.00) and 20/20,000 (logMAR 3.00), respectively. ${ }^{27}$ The paired $t$-test was used to compare visual acuity between presenting vision and those obtained at final follow-up. In all analyses, a two-tailed $P$-value of less than 0.05 was taken to indicate statistical significance.

\section{Results}

There were 1,259 consecutive patients with RRD during the study period. Twelve eyes in ten patients had RRD secondary to viral retinitis. The prevalence of viral retinitis-related RRD was therefore $0.95 \%$ (12 of 1,259). Among the ten patients, there were four males and six females (Table 1). The mean age of patients was 49.5 \pm 19.7 years (range 24-75 years). The left eye was affected in $58.3 \%$ of cases (seven of 12 ), and there were two $(16.7 \%)$ cases of bilateral viral retinitis. Patients were followed for a mean period of 4.4 years (standard deviation 2.2 years, range $1.5-8$ years, median 1.8 years). PCR analysis was available for all patients, and identified VZV in six patients, HSV in two, and CMV in two (Table 1).

Three patients had active immunosuppression, including one with Fanconi syndrome (case 1), one with HIV without AIDS (case 2), and one patient with neurosarcoid (case 7 , Table 1). One patient in remission with hairy-cell leukemia (case 10) had been immunosuppressed, but was immunocompetent at the time of viral retinitis diagnosis. Two patients had a preceding history of ipsilateral HZV shingles - 10 days and 6 weeks - prior to the development of viral retinitis (cases 9 and 10, Table 1).

All patients were initially treated with systemic antivirals: eight patients with oral valacyclovir (1 g TID) and two patients with intravenous acyclovir induction $\left(1,500 \mathrm{mg} / \mathrm{m}^{2}\right.$ body surface area in three divided doses), followed by maintenance therapy with oral valacyclovir (1 g TID). The two patients with CMV were treated with valganciclovir $(900 \mathrm{mg}$ twice daily) in addition to concomitant valacyclovir (1 $\mathrm{g}$ TID). Five patients were treated with oral prednisone in addition to antiviral therapy. Four patients received intravitreal injections of foscarnet $(2.4 \mathrm{mg} / 0.1 \mathrm{cc}$ ) (Table 1). Treatment duration consisted of an induction phase ranging from 4 to 6 weeks and a maintenance phase of a minimum 3 months after induction.

Mean presenting Snellen visual acuity ranged between 20/40 to HM (median 20/100, mean 1.09 $0.96 \log$ MAR units). Mean final Snellen visual acuity ranged from 20/30 
Table I Patient demographics, clinical features, and medical treatment

\begin{tabular}{|c|c|c|c|}
\hline Case: age (years), sex & PCR diagnosis & Systemic factors and immune status & Medical treatment \\
\hline $\mathrm{I}: 28, \mathrm{~F}$ & CMV & $\begin{array}{l}\text { Fanconi syndrome, immunosuppression, bone } \\
\text { marrow transplant, graft-versus-host disease }\end{array}$ & $\begin{array}{l}\text { Valacyclovir (Ig TID), valganciclovir (900mg } \\
\text { BID) }\end{array}$ \\
\hline 2: $33, M$ & CMV & $\begin{array}{l}\text { HIV without AIDS (CD4 } 297 \text { cells } / \mathrm{mm}^{3} \text {, HIV viral } \\
\text { load 25,000), neurosyphilis }\end{array}$ & $\begin{array}{l}\text { Valacyclovir (Ig TID), valganciclovir }(900 \mathrm{mg} \\
\text { BID), prednisone }(60 \mathrm{mg} \text { daily), intravitreal } \\
\text { foscarnet }(2.4 \mathrm{mg} / 0.1 \mathrm{cc})\end{array}$ \\
\hline 3: $60, M$ & HSV & No significant medical history & $\begin{array}{l}\text { Acyclovir (I,500 mg/m² body surface area), } \\
\text { valacyclovir (Ig TID), intravitreal foscarnet } \\
(2.4 \mathrm{mg} / 0 . \mathrm{Icc}), \text { prednisone ( } 60 \mathrm{mg} \text { daily) }\end{array}$ \\
\hline 4: $25, \mathrm{~F}$ & HSV & History of herpetic encephalitis & $\begin{array}{l}\text { Acyclovir ( } 1,500 \mathrm{mg} / \mathrm{m}^{2} \text { body surface area), } \\
\text { valacyclovir (Ig TID), prednisone ( } 60 \mathrm{mg} \text { daily) }\end{array}$ \\
\hline 5: 57, F & VZV & No significant medical history & $\begin{array}{l}\text { Valacyclovir (Ig TID), intravitreal foscarnet } \\
(2.4 \mathrm{mg} / 0 . \mathrm{Icc})\end{array}$ \\
\hline 6: $24, M$ & VZV & Autism & Valacyclovir (Ig TID) \\
\hline 7: 75, F & VZV & $\begin{array}{l}\text { Neurosarcoid, active immunosuppression with } \\
\text { methotrexate, azathioprine, prednisone }\end{array}$ & Valacyclovir (Ig TID) \\
\hline 8: 67, F & VZV & No significant medical history & Valacyclovir (Ig TID) \\
\hline $9: 66, \mathrm{~F}$ & VZV & $\begin{array}{l}\text { Antecedent history of ipsilateral shingles } 10 \text { days } \\
\text { prior to development of ARN }\end{array}$ & $\begin{array}{l}\text { Valacyclovir (Ig TID), prednisone ( } 40 \mathrm{mg} \text { daily), } \\
\text { intravitreal foscarnet }(2.4 \mathrm{mg} / 0 . \mathrm{Icc})\end{array}$ \\
\hline 10: 60, M & VZV & $\begin{array}{l}\text { Antecedent history of ipsilateral shingles } 6 \text { weeks } \\
\text { prior to development of ARN, remission for hairy- } \\
\text { cell leukemia }\end{array}$ & Valacyclovir (Ig TID), prednisone (60mg daily) \\
\hline
\end{tabular}

Abbreviations: M, male; F, female; CMV, cytomegalovirus; HSV, herpes simplex virus; VZV, varicella zoster virus; TID, ter in die (three times a day); BID, bis in die (twice daily); ARN, acute retinal necrosis.

to HM (median 20/1,250, mean 1.74 \pm 1.07 logMAR units) (Table 2). The deterioration in visual acuity of $0.65 \log M A R$ units was statistically significant $(P=0.005)$. Time to RRD from initial presentation with active viral retinitis ranged from 3 weeks to 3 years (median 4.5 weeks, mean 163.25 \pm 538.18 weeks). The large standard deviation in the latter value for all cases was due to one outlier in this group (case 7), who had a delay of 3 years before the presentation of RRD secondary to viral retinitis. Excluding this outlier case, the mean time to RRD was $7.90 \pm 8.30$ weeks, with a median value of 4 weeks.

Macula-off RRD was found in 50\% of cases ( Fundus drawings for all cases are shown in Figure 1, and display significant pathologic findings at time of surgery superimposed with operative surgical interventions. In our study, optic nerve involvement was diagnosed according to

Table 2 Vision and surgical outcomes

\begin{tabular}{|c|c|c|c|c|c|c|}
\hline $\begin{array}{l}\text { Patient: } \\
\text { age, sex }\end{array}$ & $\begin{array}{l}\text { Eye(s) } \\
\text { affected }\end{array}$ & $\begin{array}{l}\text { Presenting } \\
\text { visual acuity }\end{array}$ & $\begin{array}{l}\text { Final visual } \\
\text { acuity }\end{array}$ & $\begin{array}{l}\text { Prophylactic } \\
\text { laser retinopexy } \\
\text { (yes/no) }\end{array}$ & $\begin{array}{l}\text { Time to retinal detachment (weeks); retinal } \\
\text { detachment macula status (on/off); optic } \\
\text { nerve involvement (yes/no); vitrectomy gauge }\end{array}$ & Surgical treatment \\
\hline $\mathrm{I}: 28, \mathrm{~F}$ & $\begin{array}{l}\text { OD, then } \\
\text { OS }\end{array}$ & $20 / 40,20 / 60$ & $\mathrm{HM}, 20 / 80$ & No & $\begin{array}{l}4 \text { OD and } 5 \text { OS; macula-off OD and macula-on OS; } \\
\text { yes OD, no OS; } 23 \mathrm{~g} \text { OD and } 20 \mathrm{~g} \text { OS }\end{array}$ & PPV, SB, SO OU \\
\hline 2: $33, M$ & OS & $\mathrm{HM}$ & HM & No & 4; macula-off; yes; $20 \mathrm{~g}$ & PPV, SB, lensectomy, SO \\
\hline 3: $60, M$ & OS & $20 / 200$ & $20 / 30$ & Yes & I0; macula-off; no; $23 \mathrm{~g}$ & PPV, SB, SO \\
\hline 4: $25, \mathrm{~F}$ & os & $20 / 100$ & $20 / 250$ & No & 3; macula-on; yes; 20g & PPV, SB, SO \\
\hline 5: 57, F & OS & $20 / 800$ & $\mathrm{CF}$ & Yes & 4; macula-on; yes; $23 \mathrm{~g}$ & CE, PCIOL, PPV, SO \\
\hline $6: 24, M$ & $\begin{array}{l}\text { OD, then } \\
\text { OS }\end{array}$ & $20 / 100,20 / 40$ & HM, 20/70 & Yes & $\begin{array}{l}4(\mathrm{OU}) \text {; macula-on (OU); yes OD, no OS; } 20 \mathrm{~g} \text { OD } \\
\text { and } 20 \mathrm{~g} \text { OS }\end{array}$ & PPV, SB, SO OU \\
\hline 7: 75, F & OS & $20 / 50$ & $20 / 600$ & No & I,872 (3 years); macula-off; yes; $25 \mathrm{~g}$ & PPV, SB, SO \\
\hline 8: $67, \mathrm{~F}$ & OS & $20 / 80$ & $20 / 300$ & No & 8; macula-on; yes; $20 \mathrm{~g}$ & $P P V, S B, 18 \% \mathrm{C}_{3} \mathrm{~F}_{8}$ \\
\hline $9: 66, \mathrm{~F}$ & OD & $\mathrm{HM}$ & HM & No & 9; macula-off; yes; $20 \mathrm{~g}$ & PPV, lensectomy, SO \\
\hline 10: $60, \mathrm{M}$ & OS & $20 / 200$ & $20 / 1,250$ & Yes & 32; macula-off; yes; 23g & PPV, SB, SO \\
\hline
\end{tabular}

Notes: Column I shows the age and sex for each of the patients. Column 2 displays the eye(s) affected. Presenting and final visual acuity are displayed in columns 3 and 4 , respectively; visual acuity of "counts fingers" (CF) was recorded as 20/2,000, and hand motion (HM) recorded as 20/20,000 for statistical analysis. ${ }^{27}$ Column 5 shows patients who received prophylactic laser retinopexy prior to occurrence of retinal detachment. Column 6 summarizes time to retinal detachment for each eye, as well as if the macula was attached at the time of surgery and whether the optic nerve appeared to be involved. Surgical treatment is displayed in column 7.

Abbreviations: M, male; F, female; OD, oculus dexter (right eye); OS, oculus sinister (left eye); PPV, pars plana vitrectomy; SB, scleral buckle; SO, silicone oil; OU, oculus utro (both eyes); $\mathrm{CE}$, cataract extraction; $\mathrm{PClOL}$, posterior-chamber intraocular lens. 
A

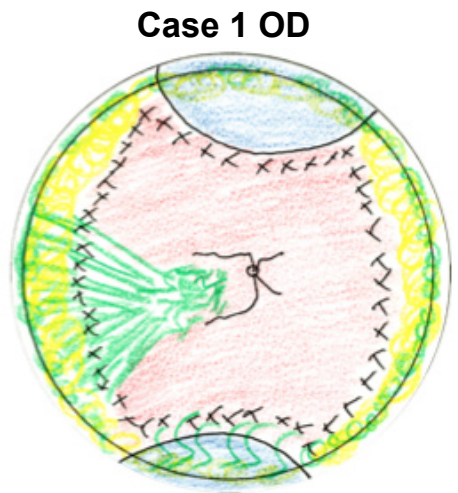

D

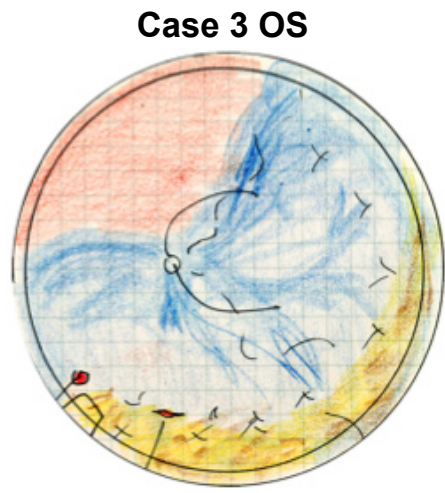

G

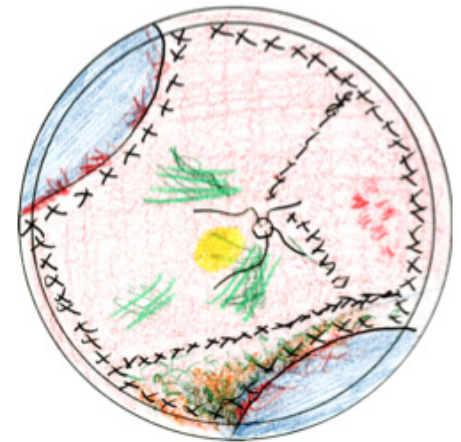

J

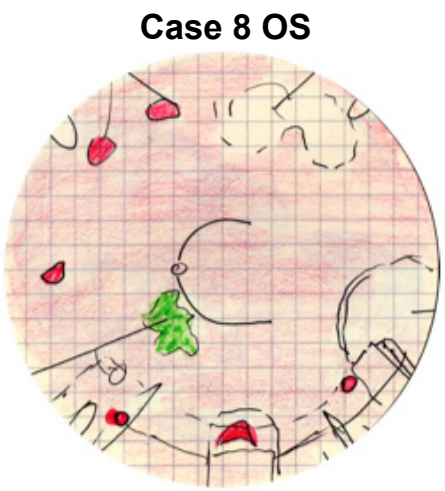

B

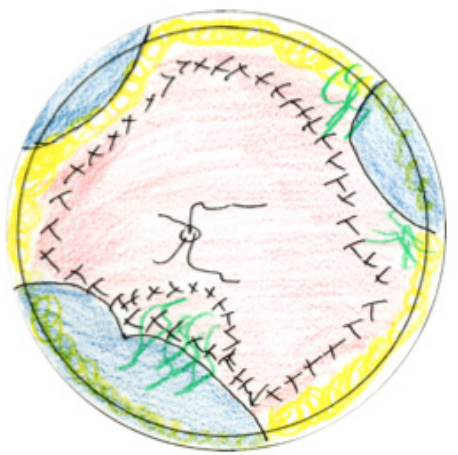

E

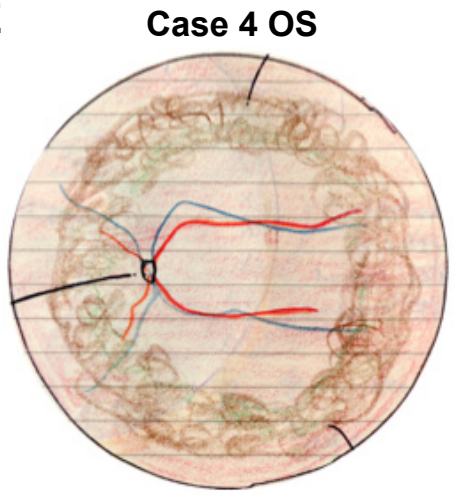

H

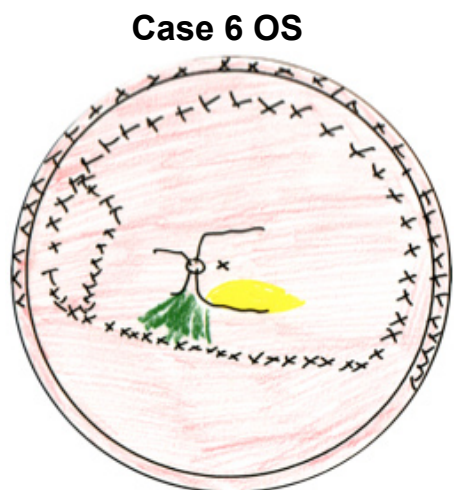

K

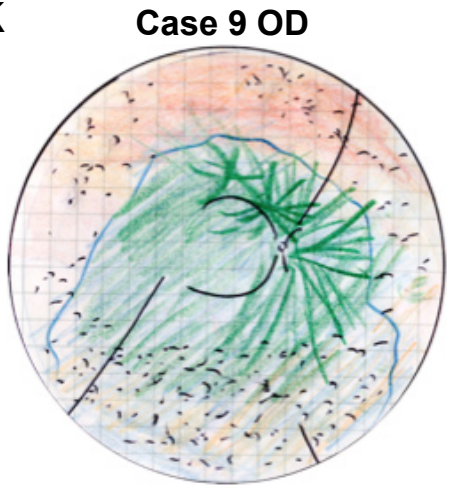

C

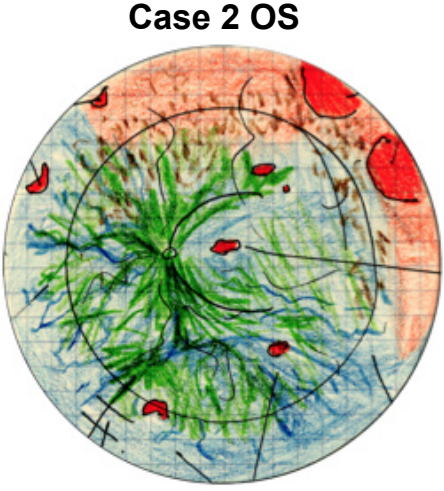

F

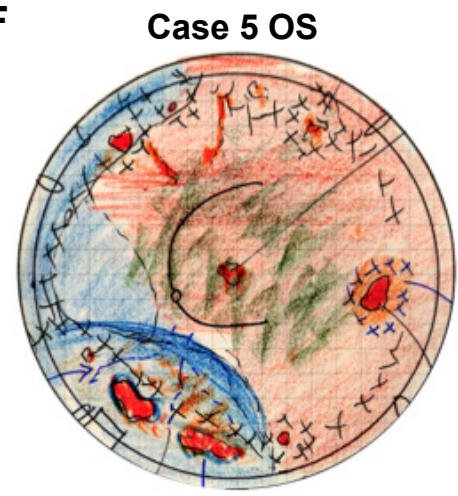

I

Case 7 OS

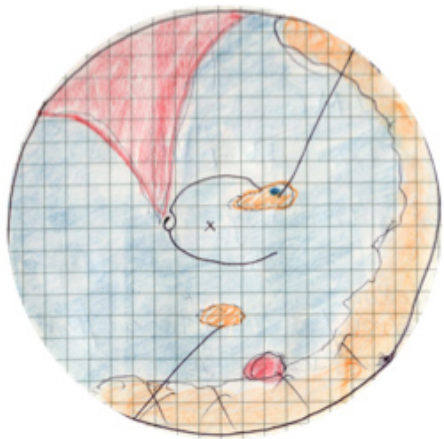

L Case 10 os

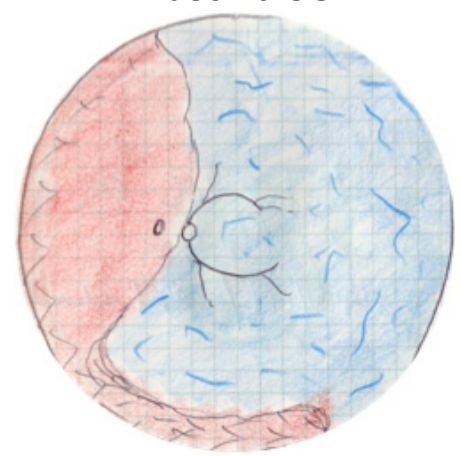

Figure I Fundus drawings.

Notes: Preoperative rhegmatogenous retinal detachment (RRD) cases secondary to acute retinal necrosis with the surgical procedures superimposed. (A and B) 28 year-old female with bilateral rhegmatogenous retinal detachment (RRD). (C) 33 year-old male with RRD and optic nerve involvement. (D) 60 year-old male with RRD but no optic nerve involvement. (E and F) Macula-on RRD with optic nerve involvement. (G and $\mathbf{H}$ ) 24 year-old male with bilateral RRD. (I) 75 year-old female with RRD. (J) 67 year-old female with macula-on RRD and optic nerve involvement. (K) 66 year-old female with macula-off RRD. (L) 60 year-old male with macula-off RRD.

Abbreviations: OD, oculus dexter (right eye); OS, oculus sinister (left eye). 
the proposed absolute and relative criteria for optic nerve involvement in viral retinitis. Absolute criteria include 1) afferent papillary defect not consistent with the retinal findings, 2) poor correlation between retinal findings and visual acuity, and 3) sudden deterioration of visual acuity to $20 / 100$ or worse without corresponding retinal changes within a 24- to 36 -hour interval. ${ }^{28}$ Optic nerve involvement occurred in $75 \%$ of cases (nine of 12). Lack of optic nerve involvement correlated with having a final visual acuity of better than 20/100: case 1, oculus sinister (OS [left eye]; final visual acuity 20/80); case 3 (final visual acuity 20/30); and case 6, OS (final visual acuity 20/70) (Tables 1 and 2).

All cases underwent three-port pars plana vitrectomy (PPV) with induction of a posterior-vitreous detachment if not already present. Membrane peeling was performed in five cases (cases 2, 3 [OS], 7, 8, and 9) when inflammatory vitreal and retinal membranes were present. Similarly, retinotomies and retinectomies were performed in four cases (cases 1 [OS], 5, and 6 [oculus utro $\{\mathrm{OU}$ (both eyes) $\}$ ]) to remove necrotic retina or achieve attachment of the posterior pole. Vitrectomy gauge varied: seven cases with 20 -gauge, four cases with 23-gauge, and one case with 25-gauge (Table 2). Endolaser demarcation of retinal areas was performed during PPV. Tamponade with 1,000 cSt silicone oil was performed in eleven of 12 eyes; the remaining eye underwent tamponade with $18 \% \mathrm{C}_{3} \mathrm{~F}_{8}$ intraocular gas (Table 2 ). In ten eyes (83.3\%), a scleral buckle was placed at the time of PPV. Initial surgery provided successful anatomic reattachment of the retina in all cases, and there were no cases of redetachment during the follow-up period. In $50 \%$ of eyes (six of 12), silicone oil was successfully removed at a later date with no occurrence of retinal redetachment during the study period. In five eyes (41.7\%; case 1 [OU], case 2, case 5, and case 9) silicone oil was left in as permanent tamponade at the discretion of the surgeon when they were concerned about a high likelihood for redetachment. There were no cases of hypotony at any time, and the lowest intraocular pressure documented during the follow-up period was $7 \mathrm{mmHg}$ (case 4). There were no cases of lowest intraocular pressure greater than 30 at any time during follow-up.

\section{Discussion}

Our results indicated the most frequent cause of viral retinitis was VZV, which is consistent with the existing literature. , $^{6,-10,24}$ The clinical findings of CMV-associated viral retinitis (cases 1 and 2) were similar to the other patients, in that there was prominent inflammation and multifocal lesions. Case 1 had long-term suppression for Fanconi syndrome, while case 2 was diagnosed with HIV without AIDS at presentation.
The clinical findings of viral retinitis typical of ARN in this HIV-positive patient were possibly due to the fact that the CD4 count of 297 cells $/ \mathrm{mm}^{3}$ afforded some immune response with intraocular inflammation. These findings highlight that CMV-associated retinitis should be considered in the diagnostic differential even in patients who are not severely immunocompromised.

There is evidence that patients with viral retinitis tend to demonstrate variable immune dysregulation. ${ }^{29}$ Our study contained three patients with immunocompromised status (cases 1, 2, and 7); additionally, three other patients may have had milder forms of immune dysregulation, given a history of herpetic encephalitis (case 4), shingles shortly before the retinitis (case 9), and one patient in remission for hairy-cell leukemia who also developed shingles before the retinitis (case 10). Five patients showed no evidence of an immunocompromised status or immune dysregulation.

In patients with severe immunosuppression, progressive outer retinal necrosis tends to be bilateral and presents with a predilection for the posterior pole with satellite lesions and lack of vitreous cells. ${ }^{30}$ Given its early involvement of the macula and posterior pole, progressive outer retinal necrosis usually causes a dramatic drop in visual acuity at presentation, and two-thirds of eyes progress to no lightperception vision within 4 weeks of onset. ${ }^{31}$ Intravitreal ganciclovir offers a targeted approach, and may result in better visual outcomes for these patients. ${ }^{32}$ Interestingly, we found five cases $(42 \%)$ of viral retinitis with macular pathology (cases 2, 5, 6 [OU], and 7 in Figure 1; case 5 in Figure 2), despite the clinical scenario being consistent with ARN. This finding did not correlate with immune status or visual acuity, but illustrates that viral retinitis may present with posterior-pole pathology. To our knowledge, this finding has not been reported in the literature, possibly because it is not included in the ARN diagnostic clinical criteria.

As mentioned previously, herpetic encephalitis and VZV shingles may exemplify cases of subtle immune dysregulation. Case 4 presented with HSV-associated ARN and a history of herpetic encephalitis. It has been shown that there is herpetic central nervous system disease in approximately $18 \%$ of patients with ARN, ${ }^{5}$ and our study supports this observation. Two other cases (9 and 10) had recent ipsilateral dermatomal shingles and went on to develop VZV-associated ARN within 6 weeks of the shingles episode. The recommendation that patients with past herpetic disease be advised to seek prompt medical attention if they develop visual symptoms is pertinent, given the proportion of viral retinitis cases that may present with this history. 

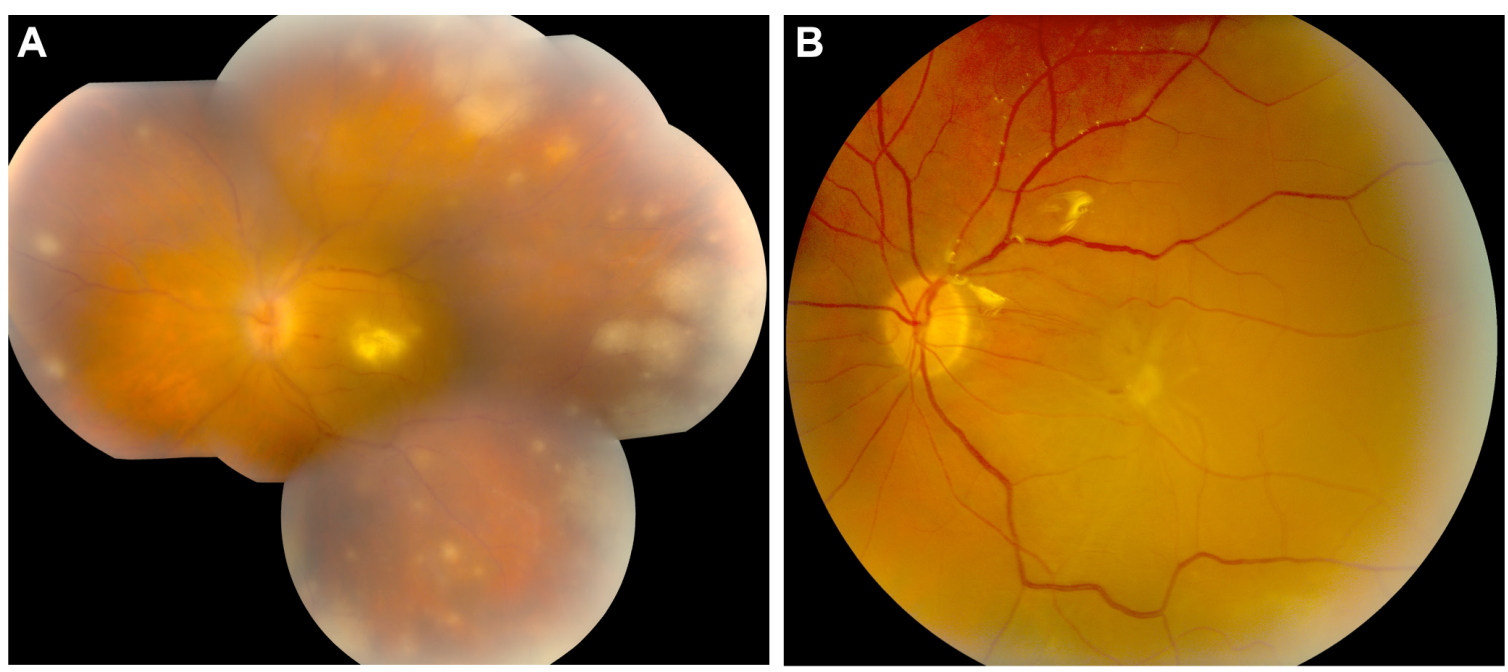

Figure 2 Acute retinal necrosis with macular and optic nerve involvement (case 5).

Notes: (A) Preoperative color fundus photography of case 5 illustrates retinal whitening in the macula with peripheral retinal necrosis. There is optic nerve involvement, with disk hyperemia and edema. There is moderate vitritis with a macula-off rhegmatogenous retinal detachment. Presenting visual acuity was 20/800. (B) Postoperative color fundus photography 2 months after cataract extraction with placement of a posterior-chamber intraocular lens and 23-gauge pars plana vitrectomy with silicone-oil tamponade. Final visual acuity was "counts fingers".

Visual outcomes in our group of patients were poor but consistent with the existing literature. ${ }^{21-24}$ The average mean presenting visual acuity of approximately 20/250 deteriorated significantly to about 20/1,100 at last follow-up, despite successful retinal reattachment surgery in all cases. Our data suggest that visual acuity prognosis is most related to optic nerve involvement and not RRD. Overall, only three patients had a final visual acuity better than 20/100 (patient 1 [OS] 20/80, patient 3 20/30 [Figure 3]; patient 6 [OS] 20/70), and this correlated with the only cases of viral retinitis lacking optic nerve involvement. Similar to what was found by
Hillenkamp et $\mathrm{al}^{6}$ this suggests that retinal and optic nerve ischemia and subsequent optic atrophy from occlusive vasculitis, rather than RRD, may be the main cause of the poor visual outcomes in patients with viral retinitis.

As described earlier, optic nerve involvement was determined according to the proposed absolute and relative criteria for optic nerve involvement in ARN. Absolute criteria include 1) afferent papillary defect not consistent with the retinal findings, 2) poor correlation between retinal findings and visual acuity, and 3) sudden deterioration of visual acuity to $20 / 100$ or worse without corresponding retinal changes
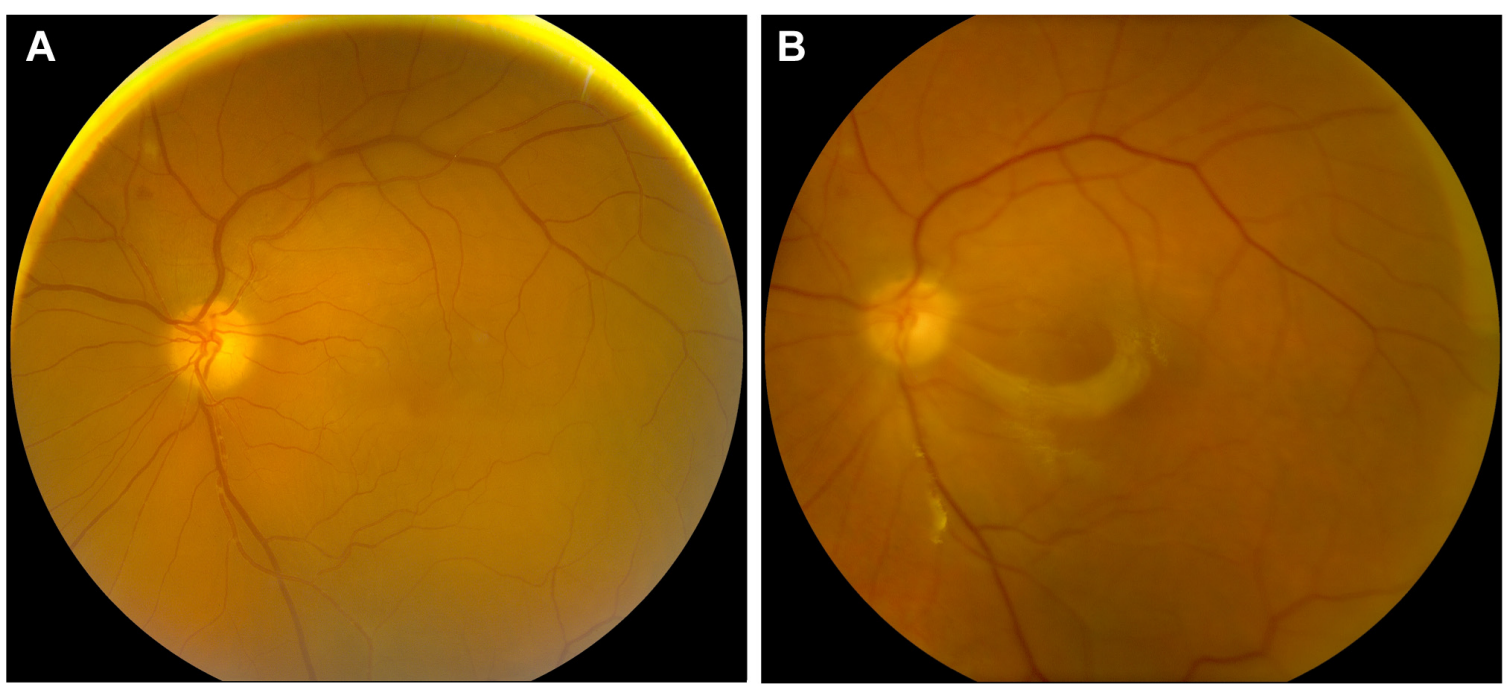

Figure 3 Macula-off rhegmatogenous retinal detachment secondary to acute retinal necrosis (case 3).

Notes: (A) Preoperative color fundus photography of case 3 illustrates a macula-off rhegmatogenous retinal detachment with no posterior pole involvement, including no optic nerve involvement. Presenting visual acuity was 20/200. (B) Postoperative color fundus photography I week after 23-gauge pars plana vitrectomy with scleral buckle and silicone-oil tamponade. Final visual acuity was $20 / 30$. 
within a 24 - to 36 -hour interval. ${ }^{28}$ Relative criteria for optic nerve involvement demonstrated on either computerized tomography and/or B-scan echography were 1) optic disk edema, and 2) enlarged optic nerves and surrounding peripapillary space. ${ }^{28}$ Optic nerve involvement is estimated to range from $47 \%$ to $57 \%$ of cases, ${ }^{33}$ although we found optic nerve involvement in $75 \%$ of our series. Several mechanisms have been proposed to explain the optic neuropathy associated with ARN, and this is likely related to intraneural vasculitis, loculated exudates within the optic nerve sheath causing compressive ischemia, and inflammation and necrosis due to direct herpes virus infection..$^{33}$ This finding may be useful when counseling patients - both at time of presentation and before retinal reattachment surgery - as visual acuity seems unlikely to improve in these cases and subsequent interventions are primarily aimed at preventing fellow-eye involvement, chronic RRD, and phthisis bulbi.

Our method of antiviral treatment was oral valacyclovir at a dose of $1 \mathrm{~g}$ TID. This was utilized in eight patients, and caused resolution of the viral retinitis. Successful control of the retinitis was also achieved in the remaining two patients with intravenous acyclovir-induction therapy followed by oral valacyclovir therapy at $1 \mathrm{~g}$ TID. The only exception occurred in case 7, a 75-year-old female with neurosarcoid. She initially presented with VZV-associated ARN that was successfully treated with valacyclovir $1 \mathrm{~g}$ TID. However, 3 years later, she presented with recurrent ARN and RRD in one eye after stopping oral valacyclovir. The fact that she required immunosuppression with three agents to control her neurosarcoid over the follow-up period is a possible reason for recurrence. It remains difficult to ascertain what additional measures should be carried out for these very high-risk individuals with a history of viral retinitis. The excellent oral bioavailability, central nervous system penetration, and ease of administration make valacyclovir ideal for the treatment of viral retinitis. Although intravenous acyclovir was used successfully in two patients, HSV resistance to acyclovir is well documented to occur in $1 \%$ of immunocompetent patients and in up to $14 \%$ of immunosuppressed patients on antiviral therapy. ${ }^{34,35}$

Our study found that the median time to RRD in cases of viral retinitis was approximately 4-4.5 weeks, with seven patients presenting with RRD at or before 5 weeks from their initial presentation; this is shorter than the median time of 53 days found by Tibbetts et al. ${ }^{3}$ Primary repair with vitrectomy using silicone-oil tamponade (eleven of 12 cases) and scleral buckle (ten of 12 cases) resulted in successful anatomical retinal reattachment with no cases of subsequent RRD. Silicone-oil placement allows for a consistent, long-term tamponade. Although silicone oil could only be removed in approximately $50 \%$ of our cases, the current stability of $1,000 \mathrm{cSt}$ silicone oil may be preferable for tamponade after RRD from viral retinitis. The decrease in visual acuity from intraocular silicone oil was not a significant issue in patients with ARN, as visual acuity outcomes are guarded, especially in light of optic nerve involvement.

The role of prophylactic vitrectomy in cases of ARN is controversial, with some reports showing improved outcomes with early surgical intervention, ${ }^{6}$ while others demonstrated no difference or worse outcomes (depending on extent of disease) with prophylactic vitrectomy ${ }^{36}$ Although we did not analyze the role of prophylactic vitrectomy in our study, we found that timely surgery at onset of RRD allowed for stable anatomical results in all cases over a long period of follow-up. The reported literature varies widely on surgical techniques and outcomes for viral retinitis. ${ }^{3,6,22,24,25,36}$ Our results suggest the approach for RRD secondary to viral retinitis in this study can lead to anatomic success without subsequent RRD or hypotony.

The follow-up in our study was a mean value of approximately 4.3 years (range 1.5-8 years), and represents one of the longest follow-ups of viral retinitis patients in the literature. Accessibility to this long period of follow-up greatly aids our study resolution in extrapolating meaningful clinical conclusions regarding visual acuity prognosis, stability of anatomical and surgical outcomes, and the effectiveness of oral antiviral medial therapy. Nonetheless, a limitation of our study is the small sample size and its retrospective nature.

In summary, we present the visual and anatomic outcomes of 12 consecutive cases in ten patients of RRD secondary to viral retinitis with extensive follow-up. VZV was the most frequent cause of viral retinitis; however, CMV-associated cases were frequent in immunocompromised patients. Prior herpetic disease, such as herpetic encephalitis and shingles, were relevant factors in the medical histories of patients who developed viral retinitis. These patients should be counseled to present immediately should eye symptoms occur. Oral valacyclovir seems to be a safe and efficacious treatment for viral retinitis. Vitrectomy, with silicone-oil tamponade and scleral buckle placement, was successful, with excellent anatomical results and is recommended by us for patients with RRD secondary to viral retinitis. Visual acuity outcomes where there is optic nerve involvement are poor, and indeed the dramatic decline in visual acuity in patients with viral retinitis continues to be disappointing.

\section{Author contributions}

DA and VM were responsible for the design and conduct of the study, and all authors partook in collection, management, 
analysis, and interpretation of the data, preparation, review, and approval of the paper, and the decision to submit the paper for publication.

\section{Disclosure}

The authors report no conflicts of interest in this work.

\section{References}

1. Urayama A, Yamada N, Sasaki T, et al. [Unilateral acute uveitis with retinal periarteritis and detachment]. Rinsho Ganka. 1971;25:607-619. Japanese.

2. Willerson D Jr, Aaberg TM, Reeser FH. Necrotizing vaso-occlusive retinitis. Am J Ophthalmol. 1977;84:209-219.

3. Tibbetts MD, Shah CP, Young LH, Duker JS, Maguire JI, Morley MG. Treatment of acute retinal necrosis. Ophthalmology. 2010;117: $818-824$.

4. Young NJ, Bird AC. Bilateral acute retinal necrosis. Br J Ophthalmol. 1978;62:581-590.

5. Cochrane TF, Silvestri G, McDowell C, Foot B, McAvoy CE. Acute retinal necrosis in the United Kingdom: results of a prospective surveillance study. Eye (Lond). 2012;26:370-377; quiz 378.

6. Hillenkamp J, Nölle B, Bruns C, Rautenberg P, Fickenscher H, Roider J. Acute retinal necrosis: clinical features, early vitrectomy, and outcomes. Ophthalmology. 2009;116:1971-1975.e2.

7. Holland GN. Standard diagnostic criteria for the acute retinal necrosis syndrome. Executive Committee of the American Uveitis Society. Am J Ophthalmol. 1994;117:663-667.

8. Ganatra JB, Chandler D, Santos C, Kuppermann B, Margolis TP. Viral causes of the acute retinal necrosis syndrome. Am JOphthalmol.2000;129: $166-172$.

9. Walters G, James TE. Viral causes of the acute retinal necrosis syndrome. Curr Opin Ophthalmol. 2001;12:191-195.

10. Kanoff J, Sobrin L. New diagnosis and treatment paradigms in acute retinal necrosis. Int Ophthalmol Clin. 2011;51:25-31.

11. Tran TH, Rozenberg F, Cassoux N, Rao NA, LeHoang P, Bodaghi B. Polymerase chain reaction analysis of aqueous humour samples in necrotising retinitis. Br J Ophthalmol. 2003;87:79-83.

12. Gargiulo F, De Francesco MA, Nascimbeni G, et al. Polymerase chain reaction as a rapid diagnostic tool for therapy of acute retinal necrosis syndrome. J Med Virol. 2003;69:397-400.

13. Sugita S, Shimizu N, Watanabe K, et al. Use of multiplex PCR and real-time PCR to detect human herpes virus genome in ocular fluids of patients with uveitis. Br J Ophthalmol. 2008;92:928-932.

14. Asano S, Yoshikawa T, Kimura H, et al. Monitoring herpesvirus DNA in three cases of acute retinal necrosis by real-time PCR. J Clin Virol. 2004; 29:206-209.

15. Cottet L, Kaiser L, Hirsch HH, Baglivo E. HSV2 acute retinal necrosis: diagnosis and monitoring with quantitative polymerase chain reaction. Int Ophthalmol. 2009;29:199-201.

16. Emerson GG, Smith JR, Wilson DJ, Rosenbaum JT, Flaxel CJ. Primary treatment of acute retinal necrosis with oral antiviral therapy. Ophthalmology. 2006;113:2259-2261.
17. Blumenkranz MS, Culbertson WW, Clarkson JG, Dix R. Treatment of the acute retinal necrosis syndrome with intravenous acyclovir. Ophthalmology. 1986;93:296-300.

18. Aslanides IM, De Souza S, Wong DT, et al. Oral valacyclovir in the treatment of acute retinal necrosis syndrome. Retina. 2002;22:352-354.

19. Chong DY, Johnson MW, Huynh TH, Hall EF, Comer GM, Fish DN. Vitreous penetration of orally administered famciclovir. Am JOphthalmol. 2009;148:38-42.e1.

20. Palay DA, Sternberg P Jr, Davis J, et al. Decrease in the risk of bilateral acute retinal necrosis by acyclovir therapy. Am J Ophthalmol. 1991;112: 250-255.

21. Sims JL, Yeoh J, Stawell RJ. Acute retinal necrosis: a case series with clinical features and treatment outcomes. Clin Experiment Ophthalmol. 2009;37:473-477.

22. Meghpara B, Sulkowski G, Kesen MR, Tessler HH, Goldstein DA. Longterm follow-up of acute retinal necrosis. Retina. 2010;30:795-800.

23. Tran TH, Stanescu D, Caspers-Velu L, et al. Clinical characteristics of acute HSV-2 retinal necrosis. Am J Ophthalmol. 2004;137:872-879.

24. Lau CH, Missotten T, Salzmann J, Lightman SL. Acute retinal necrosis features, management, and outcomes. Ophthalmology. 2007;114: 756-762.

25. McDonald HR, Lewis H, Kreiger AE, Sidikaro Y, Heckenlively J. Surgical management of retinal detachment associated with the acute retinal necrosis syndrome. Br J Ophthalmol. 1991;75:455-458.

26. Park JJ, Pavesio C. Prophylactic laser photocoagulation for acute retinal necrosis. Does it raise more questions than answers? Br J Ophthalmol. 2008;92:1161-1162.

27. Holladay JT. Visual acuity measurements. J Cataract Refract Surg. 2004; 30:287-290.

28. Sergott RC, Anand R, Belmont JB, Fischer DH, Bosley TM, Savino PJ. Acute retinal necrosis neuropathy. Clinical profile and surgical therapy. Arch Ophthalmol. 1989;107:692-696.

29. Guex-Crosier Y, Rochat C, Herbort CP. Necrotizing herpetic retinopathies. A spectrum of herpes virus-induced diseases determined by the immune state of the host. Ocul Immunol Inflamm. 1997;5:259-265.

30. Kashiwase M, Sata T, Yamauchi Y, et al. Progressive outer retinal necrosis caused by herpes simplex virus type 1 in a patient with acquired immunodeficiency syndrome. Ophthalmology. 2000;107:790-794.

31. Engstrom RE Jr, Holland GN, Margolis TP, et al. The progressive outer retinal necrosis syndrome. A variant of necrotizing herpetic retinopathy in patients with AIDS. Ophthalmology. 1994;101:1488-1502.

32. Gore DM, Gore SK, Visser L. Progressive outer retinal necrosis: outcomes in the intravitreal era. Arch Ophthalmol. 2012;130:700-706.

33. Witmer MT, Pavan PR, Fouraker BD, Levy-Clarke GA. Acute retinal necrosis associated optic neuropathy. Acta Ophthalmol. 2011;89: 599-607.

34. Wong RW, Jumper JM, McDonald HR, et al. Emerging concepts in the management of acute retinal necrosis. Br J Ophthalmol. 2013;97: 545-552.

35. Gilbert C, Bestman-Smith J, Boivin G. Resistance of herpesviruses to antiviral drugs: clinical impacts and molecular mechanisms. Drug Resist Updat. 2002;5:88-114.

36. Iwahashi-Shima C, Azumi A, Ohguro N, et al. Acute retinal necrosis: factors associated with anatomic and visual outcomes. Jpn JOphthalmol. 2013;57:98-103.
Clinical Ophthalmology

\section{Publish your work in this journal}

Clinical Ophthalmology is an international, peer-reviewed journal covering all subspecialties within ophthalmology. Key topics include: Optometry; Visual science; Pharmacology and drug therapy in eye diseases; Basic Sciences; Primary and Secondary eye care; Patient Safety and Quality of Care Improvements. This journal is indexed on Submit your manuscript here: http://www.dovepress.com/clinical-ophthalmology-journal

\section{Dovepress}

PubMed Central and CAS, and is the official journal of The Society of Clinical Ophthalmology (SCO). The manuscript management system is completely online and includes a very quick and fair peer-review system, which is all easy to use. Visit http://www.dovepress.com/ testimonials.php to read real quotes from published authors. 